\title{
Optimization of warehouse location through fuzzy multi-criteria decision making methods
}

\author{
C. L. Karmaker ${ }^{a^{*}}$ and M. Saha ${ }^{b}$
}

${ }^{a}$ Department of Industrial and Production Engineering, Jessore University of Science and Technology, Jessore, Bangladesh ${ }^{b}$ Department of Civil Engineering, Bangladesh University of Engineering and Technology, Dhaka, Bangladesh

\section{H R O N I C L E}

\begin{tabular}{l}
\hline Article history: \\
Received October 29, 2014 \\
Received in revised format: \\
March 2, 2015 \\
Accepted April 20, 2015 \\
Available online \\
April 232015 \\
\hline Keywords: \\
Multi criteria decision making \\
Supply chain performance \\
Fuzzy AHP \\
TOPSIS \\
Fuzzy TOPSIS \\
Warehouse location selection
\end{tabular}

\section{Introduction}

Supply chain management has become a key aspect that has implications for effective and efficient management of industrial relations. It has also become an important focus for firms and organizations to obtain a competitive advantage (Carrera \& Mayorga, 2008). In encountering an ever-increasingly competitive and quickly changing environment, companies require to reorganize their supply chain management strategy to harmonize with external environments by integrating the organizational resources, data, and activities so as to maintain competitive advantages (Lang et al., 2009). 
Warehouse, a key driver of the supply chain performance, provides economies of scale through efficient operations, storage capacity and a central location with the goal of minimizing cost and fulfillment times. Frazelle (2002) pointed out that warehouses are key aspect of modern supply chains and play a vital role in the success, or failure of businesses today. In today's world, the selection of a warehouse location has become one of the most imperative and strategic decisions in the optimization of logistic systems. Anand et al. (2012) also considered location decision as one of the strategic decisions in the fields of supply chain management (SCM) and operations management (OM).

The aim of warehouse location decision by a company is often persuade the owner, investors, partners, employees, and other stakeholders to maintain a certain point of view about it, its productivity, efficiency, revenue generation or of its total costing. Implementing the above strategy not only depends on operations but also business development, human resources, finance, etc. of that company. Strategic decision, backed by company, is to be implemented effectively to spread a business or a brand globally. Moreover, there is also evidence that retail and wholesale trade, business activity, market proximity and transport service, show a sluggish trend due to improper location selection. The moot point is that as it requires large investment and since it is irrecoverable in most of the instances, choice of a warehouse location among eligible alternatives is a very powerful decision. A poor choice of location might result in excessive transportation cost, loss of qualified labour, competitive advantage or some similar condition that would be detrimental to operations (Stevenson, 1993). As decisions regarding facilities are a crucial element in a company's quality success or failure, company must analyze in order to find a balance between responsiveness and efficiency that best matches the needs of its target customer. Frazelle (2002) pointed out that warehouses are a key aspect of modern supply chains and play a vital role in the success, or failure of businesses today. The manufacturers need to pay attention to address this challenge of selecting the most suitable location in order to ensure full workability as well as full safety of their unit. However, company may think about selection of right place. But this is just the beginning. Any company needs its vision, mission, goals and objectives, which must fulfill the need and requirement of its new location. If not, this is going to be a failed venture. At the same time, it has become imperative to undertake some pragmatic steps to select the location to comply with its mission and strategy. The general procedure for making location decisions usually consists of the following steps: Decide on the criteria that will be used to evaluate location alternatives; select the criteria that are important; develop location alternatives and select the alternatives evaluated (Stevenson, 1993).

In location selection process, the company's ultimate aim is to obtain access to locations that confirm a certain way of supply chain surplus in terms of promoting distribution performance. Location selection is a long-term decision and is influenced by many quantitative and qualitative criteria; however, some criteria are so important that they tend to dominate the decision in importance (Ashrafzadeh et al., 2012). So, in order to obtain a competitive advantage in the global business scenario, each organization has a duty to consider meaningful criteria. The location decision may fluctuate with regard to type of business. Thus, the factors considered vary from business to business but it is emphasized that the objective of the decision is to maximize the benefit of location of the firm (Heizer \& Render, 2001). In this study, the evaluation criteria for the selection decision were selected from the studies of Min and Melachrinoudis (1999), Alberto (2000), MacCarthy and Atthrirawong (2003), Demirel et al. (2010) and Dogan (2012).

Strategy selection becomes difficult as the number of alternatives and conflicting criteria increases (Dey et al., 2012). So, robust evaluation models are crucial in order to incorporate several conflicting criteria meritoriously. With its need to trade-off multiple criteria exhibiting ambiguity and fuzziness, location selection is a multi-criteria decision-making problem. Kahraman et al. (2003) pointed out that the selection of a warehouse location among alternative locations is a multi-criteria decision-making problem including both quantitative and qualitative criteria. The classical multi-criteria decision making (MCDM) methods that consider deterministic or random processes cannot effectively address 
decision problems including imprecise and linguistic information (Dursun \& Karsak, 2013). In practice, assessment of location selection comprises a high degree of ambiguity and fuzziness (Liang \& Wang, 1991). Fuzzy set theory is one of the effective tools for handling uncertainty and vagueness in the decision process.

There is an unending need for aggregation of expert opinions that prevents the bias and diminishes the unfairness in the decision process. Multiple decision-makers usually cause not only the imprecise evaluation but also serious persecution during decision process (Ertuğrul \& Karakaşoğlu, 2008). For group decision making problems, consensus is an essential indication of group agreement or reliability. In order to fully reflect the real behavior of the group, a final decision ought to be made on significant level of consensus (Dursun \& Karsak, 2013). Therefore, a group decision has been proposed to improve the pair-wise comparison in the evaluation process.

The aim of this study is to propose a model to evaluate the best warehouse location by comparing five existing locations. In the assessment procedure, FAHP method has been applied to determine the weights of the criteria and to rank the locations, two multi-criteria decision making methods TOPSIS and fuzzy TOPSIS have been used as comparatively.

The rest of this study is arranged as follows: The second section presents the literature review on warehouse allocation problem. Section 3 frameworks the developed methodology and provides a stepwise depiction of the anticipated fuzzy decision making approach. In Section 4, the application of the proposed framework for the selection of location has been given. And finally, in section five, results of the application are presented and suggestions for the future studies are clarified. This section wraps up this study.

\section{Literature review}

Recently, to acquire the competitive advantages in order to survive in the global business scenario, the selection of a warehouse location has become a remarkable concern in the business-management literature. It is seen as one of the imperious strategic issue in supply chain management. To develop supply chain performance in terms of efficiency \& responsiveness, firms must determine their locations. Modern companies are now facing the problems of selecting locations. The difficulty of the location valuation and selection problem has driven the researchers to develop models for helping decision-makers.

The location theory was first familiarized by Weber (1989). The objective of the study was to locate a warehouse aiming the reduction of total travel distance between the warehouse and end customers. In the selection process, he anticipated a material index according to which, the warehouse should be opened near the source of raw material if the value of index becomes greater than one; otherwise, it must be adjacent to the market. Tuzkaya et al. (2008) developed a structure that included qualitative and quantitative factors and tangible and intangible criteria for the evaluation of suitable undesirable facility locations by using analytic network process (ANP) technique. The study was performed on the basis on four main factors, namely, benefits, cost, opportunities and risks. Badri (1999) presented a structured approach that combines AHP and goal program modeling approach to identify the most suitable international facility location. The study used AHP to prioritize the set of location alternatives. Chan and Chung (2004) developed a hybrid approach using a combination of Genetic Algorithm and AHP methods for optimizing distribution network problems in supply chain management and established GA + AHP as a dependable and vigorous approach.

In addition to the assessable aspects of the location selection decision, soft criteria having subjective factors that are difficult to enumerate, are needed to be measured. In addition to the conventional approaches (locational cost volume analysis, factor rating, and center of gravity method), the multiple 
criteria decision-making methods such as AHP or ANP tend to be less effective in dealing with the imprecise or vague nature of the linguistic assessment for facility location problems. In real world applications, assessment of eligible alternatives for subjective criteria is expressed in linguistic terms. And also, to efficiently resolve the ambiguity frequently arising in available information and do more justice to the essential fuzziness in human judgment and preference, the fuzzy set theory has been used to establish an ill-defined multiple criteria decision-making problems (Liang, 1999). Fuzzy set theory seems to be an operative tool in dealing with the imprecise or uncertainty intrinsic in location selection process. In the literature, there are a number of studies that apply different fuzzy based decision making techniques to classify locations.

A number of studies have focused on the use of fuzzy multi-criteria decision making (MCDM) techniques for warehouse location selection process. Ashrafzadeh et al. (2012) extended the wellknown MCDM method namely technique for order preference by similarity to ideal solution (TOPSIS) to evaluate the warehouse location selection problem under fuzzy environment.

Kahraman et al. (2003) introduced four different fuzzy multi-attribute group decision making approaches to assess the supply chain driver namely facility location and made a comparison. The used approaches were: fuzzy AHP, fuzzy model of group decision proposed by Blin, fuzzy synthetic evaluation and Yager's weighted goals method. Farahani and Asgari (2007) offered a structured framework of fusion multi-attribute and multi-objective set covering problem that integrates TOPSIS and utility function (from global criterion method) for locating military warehouses. Dey et al. (2012) proposed fuzzy extended multi-objective optimization on the basis of ratio analysis (MOORA) for its simplicity and applicability to identify one of the supply chain strategies namely warehouse location selection.

A few researchers have employed the comparative analysis of MCDM techniques in location selection process. Ertuğrul \& Karakaşoğlu (2008) proposed a comparative analysis of fuzzy AHP and fuzzy TOPSIS methods for evaluating facility location of a textile company. In this research, a fuzzy multicriteria group decision making approach has been utilized. To reduce fuzziness, the weights of location selection criteria have been estimated by using fuzzy analytic hierarchical process. Then, the final ranking of the eligible candidates is attained by using TOPSIS and fuzzy TOPSIS methods. This research is considered to the literature, because it is first to develop a structured framework that integrates fuzzy AHP for determining weights and TOPSIS as well as fuzzy TOPSIS to rank alternatives.

\section{MCDM methods}

Multiple-criteria decision analysis (MCDA) or Multiple-criteria decision making (MCDM) is a subdiscipline and full-grown branch of operations research that is concerned with designing mathematical and computational tools to support the subjective evaluation of a finite number of decision alternatives under a finite number of performance criteria by a single decision maker or by a group (Lootsma, 1999). MCDM refers to screening, prioritizing, ranking, or selecting a set of alternatives under usually independent, incommensurate or conflicting attributes ( Hwang \& Yoon, 1981). Determining the attributes is very crucial to MCDM as they play a very substantial role in the decision making process. Several methods have been proposed for solving related problems, but a major problem of MADM is that different techniques may yield different results for the same problem. Therefore, how to make trade-off between these conflicting attributes and then make a decision could pose a difficult problem (Cheng et al., 2012).The evaluation procedure in this paper consists of four main steps as summarized in Fig. 1. 


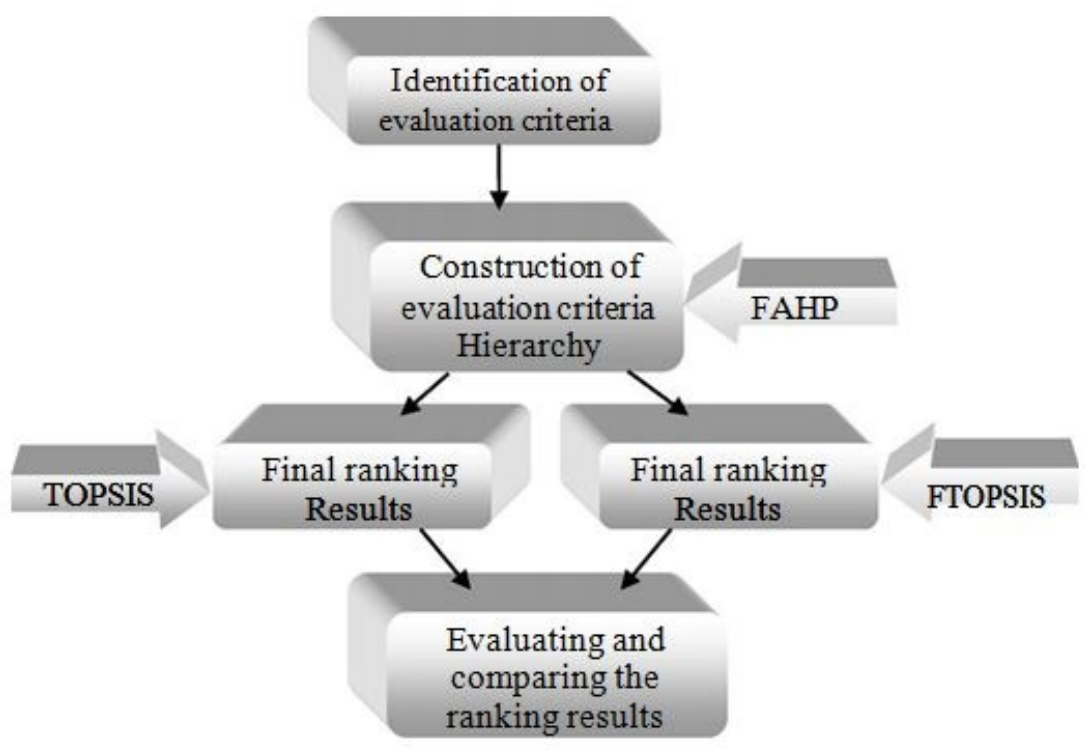

Fig.1. Steps of evaluation procedure

Step 1: Identify the evaluation criteria considered as the most important performance measures for the allocation problem.

Step 2: Construct the hierarchy of the evaluation criteria and calculate the weights of these criteria using FAHP method.

Step 3: Conduct the TOPSIS and FTOPSIS methods to achieve the final ranking results.

Step 4: Evaluate and compare the ranking results according to both methods.

The detailed descriptions of each step are illustrated in the following sections.

\subsection{Determining the criteria weights by FAHP}

The analytic hierarchy process (AHP) is a multiple criteria decision making tool for organizing and analyzing complex decisions and firstly developed by Saaty (1980). Although the AHP is to capture the expert's knowledge, Davoudi and Shykhvand (2012) state that due to the uncertainty in the judgments of participants, the crisp pairwise comparison in the conventional AHP is insufficient and imprecise to capture the right judgments. The traditional AHP method is problematic in that it uses an exact value to express the decision maker's opinion in a comparison of alternatives (Wang \& Chen, 2007). AHP method is often criticized due to its use of unbalanced nine-point scale of judgments and its inability to adequately handle the inherent uncertainty and imprecision in the pair-wise comparison process (Deng, 1999). Therefore, conventional AHP seems inadequate to capture decision maker's requirements explicitly (Kabir \& Hasin, 2011). As some of the evaluation criteria are subjective and qualitative in nature, fuzzy analytic hierarchy process (FAHP) is developed as an alternative to alleviate the deficiencies of the classical AHP and to ease the adaptation to real life problems through the linguistics variables represented by triangular fuzzy numbers (TFN) as an extension of AHP. Özdağoğl and özdağoğlu (2007) state that fuzzy Analytical Hierarchy Process (FAHP) is a synthetic extension of classical AHP method when the fuzziness of the decision makers is considered.

The first study with FAHP was carried out by Van Laarhoven and Pedrycz (1983). To extract the weights in different multi criteria comparison environments, a variety of FAHP methods have been 
widely applied in the literature: Constrained FAHP (Enea \& Piazza, 2004) for project selection, linear goal programming (LGP) priority method in new product development project, fuzzy prioritization method (Milkhailov \& Tsvetinov, 2004) for the service evaluation process, four approaches namely fuzzy model by Blin, fuzzy synthetic evaluation, Yager's weighted goals method and FAHP (Kahraman et al., 2003) for facility location selection, extent analysis method (Chang, 1992, 1996), geometric mean technique (Buckley, 1985), two-stage logarithmic programming (Wang et al., 2005), the fuzzy least square method (Xu, 2000), the direct fuzzification of the method of Csutora \& Buckley (2001) are some of these methods. Among various techniques embedded in fuzzy AHP, extent analysis method proposed by Chang $(1992,1996)$ is a popular approach to determine the weight of criteria (e.g., Kahraman et al.2004). In this research, Chang's extent analysis method is employed to obtain the weight of criteria.

\subsubsection{Fuzzy sets and fuzzy numbers}

As human judgements and preferences are vague and 'not very clear’, “'probably so”, “very likely”, these terms of expression are very common in decision making, precise numerical values seem to be inadequate to solve real world problems. Many real-world applications cannot be described and handled by classical set theory (Chen \& Pham, 2001) because it contains objects that satisfy precise properties required for membership. A structured framework must be considered in decision making process that takes into account human subjectivity, rather than employing only objective probability measures. Fuzzy sets are a generalization of conventional set theory that was introduced by Zadeh in 1965 as a mathematical way to represent vagueness in everyday life. This theory provides a different way to view the problem of modeling uncertainty and offers a wide range of computational tools to aid decision making. Thus the vague data may be represented by fuzzy numbers. If a fuzzy set is convex and normalized, and its membership function is defined in R and piecewise continuous, it is called as "fuzzy number".

So, we have to underscore the use of different fuzzy numbers depending on different situations. Such a situation in practice is intended to use specially triangular and trapezoidal fuzzy numbers of which it is often convenient to work with triangular fuzzy numbers (TFNs) due to easiness in computational procedures. In this paper, TFNs are recommended in order to represent the linguistic variables. A TFN is described as $M=(l, m, u)$ where the parameters express the smallest possible value, the most promising value, and the largest possible value for describing a fuzzy event respectively. A triangular fuzzy number (TFN) $M$ is illustrated in Fig. 2. (Deng, 1999).

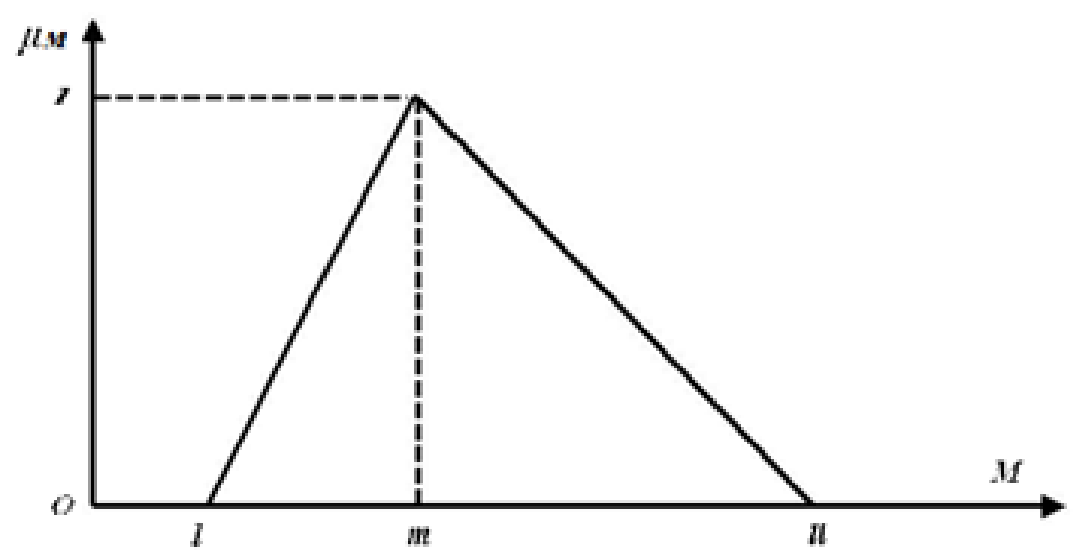

Fig. 2. Triangular fuzzy number $(M)$ 
Among various operations on triangular fuzzy numbers three important operations are used in this paper. Let $M_{1}=\left(a_{1}, b_{1}, c_{1}\right)$ and $M_{2}=\left(a_{2}, b_{2}, c_{2}\right)$ be two positive triangular fuzzy numbers, the basic operations of triangular fuzzy numbers are defined as follows (Kaufmann \& Gupta, 1991):

$$
\begin{aligned}
& M_{1} \oplus M_{2}=\left(a_{1}+a_{2}, b_{1}+b_{2}, c_{1}+c_{2}\right) \\
& M_{1} \otimes M_{2}=\left(a_{1} \cdot a_{2}, b_{1} \cdot b_{2}, c_{1} \cdot c_{2}\right) \\
& M_{1}^{-1} \approx\left(1 / c_{1}, 1 / b_{1}, 1 / a_{1}\right)
\end{aligned}
$$

\subsubsection{The methodology of FAHP}

In this study, the extent FAHP is utilized, which was originally introduced by Chang $(1992,1996)$ for handling pair-wise comparison scale based on triangular fuzzy numbers (TFNs) followed by use of extent analysis method for synthetic extent value of the pair-wise comparison. Let $X=$ $\left\{x_{1}, x_{2}, \ldots \ldots \ldots, x_{n}\right\}$ an object set, and $U=\left\{u_{1}, u_{2}, \ldots \ldots \ldots, u_{n}\right\}$ be a goal set. As per Chang $(1992,1996)$ then each object is taken and extent analysis for each goal is performed respectively. Therefore, $\mathrm{m}$ extent analysis values for each object can be obtained, with the following signs:

$M_{g i}^{1}, M_{g i}^{2}, \ldots ., M_{g i}^{m}, \quad i=1,2, \ldots, n$

Where $M_{g i}^{j}(j=1,2, \ldots, m)$ are TFNs whose parameters are depicting least, most and largest possible values respectively and represented as $(a, b, c)$. The steps of Chang's extent analysis (Chang, 1992, 1996) can be detailed as follows (Bozbura et al., 2007; Kahraman et al., 2004; Kabir \& Hasin, 2011):

Step 1: The value of fuzzy synthetic extent with respect to the ith object is defined as

$$
S_{i}=\sum_{j=1}^{m} M_{g i}^{j} \otimes\left\lceil\sum_{i=1}^{n} \sum_{j=1}^{m} M_{g i}^{j}\right\rceil^{-1}
$$

To obtain $\sum_{j=1}^{m} M_{g i}^{j}$, the fuzzy addition operation of $m$ extent analysis values for a particular matrix is performed such as

$$
\sum_{j=1}^{m} M_{g i}^{j}=\left(\sum_{j=1}^{m} a_{j,} \sum_{j=1}^{m} b_{j,} \sum_{j=1}^{m} c_{j}\right)
$$

to obtain $\left[\sum_{j=1}^{n} \sum_{j=1}^{m} M_{g i}^{j}\right]^{-1}$, the fuzzy addition operation of $M_{g i}^{j}(j=1,2, \ldots, m)$ values is performed such as

$$
\sum_{i=1}^{n} \sum_{i=1}^{m} M_{g i}^{j}=\left(\sum_{i=1}^{n} a_{j} \sum_{i=1}^{n} b_{j,} \sum_{i=1}^{n} c_{j}\right)
$$

And then inverse of the vector above is computed, such as 


$$
\left\lceil\sum_{i=1}^{n} \sum_{j=1}^{m} M_{g i}^{j}\right]^{-1}=\left(\frac{1}{\sum_{i=1}^{n} c_{i}}, \frac{1}{\sum_{i=1}^{n} b_{i}}, \frac{1}{\sum_{i=1}^{n} a_{i}}\right)
$$

Step 2: As $M_{1}=\left(a_{1}, b_{1}, c_{1}\right)$ and $M_{2}=\left(a_{2}, b_{2}, c_{2}\right)$ are two triangular fuzzy numbers, the degree of possibility of $M_{2}=\left(a_{2}, b_{2}, c_{2}\right) \geq M_{1}=\left(a_{1}, b_{1}, c_{1}\right)$ is defined as

$$
V\left(M_{2} \geq M_{1}\right)=\sup \left[\min \left(\mu_{M_{1}}(x), \mu_{M_{2}}(y)\right)\right]
$$

And can be equivalently expressed as follows:

$$
\begin{gathered}
V\left(M_{2} \geq M_{1}\right)=h g t\left(M_{1} \cap M_{2}\right)=\mu_{M_{2}}(d) \\
=\left\{\begin{array}{cr}
1 & \text { if } b_{2} \geq b_{1} \\
0 & \text { if } a_{1} \geq c_{2} \\
\frac{a_{1}-c_{2}}{\left(b_{2}-c_{2}\right)-\left(b_{1}-a_{1}\right)} & \text { otherwise }
\end{array}\right.
\end{gathered}
$$

Fig.3. (Chang, 1996) illustrates Eq. (6) where $d$ is the ordinate of the highest intersection point $D$ between $\mu_{M_{1}}$ and $\mu_{M_{2}}$. To compare $M_{1}$ and $M_{2}$, we need both the values of $V\left(M_{1} \geq M_{2}\right)$ and $V$ $\left(M_{2} \geq M_{1}\right)$.

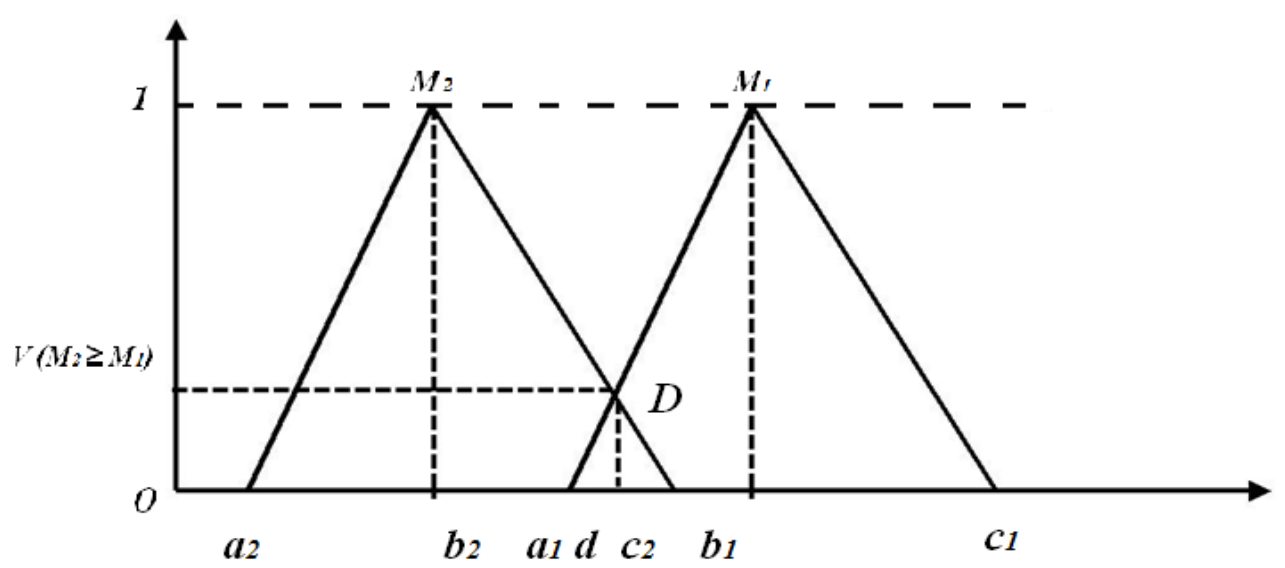

Fig. 3. The intersection between $M_{1}$ and $M_{2}$

Step 3: The degree of possibility for a convex fuzzy number to be greater than $k$ convex fuzzy $M_{i}(i=1,2, \ldots \ldots ., k)$ numbers can be defined by

$V\left(M \geq M_{1}, M_{2} \ldots \ldots, M_{k}\right)=V\left[\left(M \geq M_{1}\right)\right.$ and $(M \geq$

$\left.M_{2}\right)$ and $\ldots \ldots \ldots$ and $\left.\left(M \geq M_{k}\right)\right]$

$=\min V\left(M \geq M_{i}\right), \quad i=1,2, \ldots \ldots, k$

Assuming that $d\left(A_{i}\right)=\min V\left(S_{i} \geq S_{k}\right)$ for $k=1,2, \ldots \ldots, n ; k \neq i$. Then the weight vector is given by

$$
W^{\prime}=\left(d^{\prime}\left(A_{1}\right), d^{\prime}\left(A_{2}\right), \ldots \ldots, d^{\prime}\left(A_{n}\right)\right)^{T}
$$


where $A_{i}(i=1,2, \ldots \ldots . ., n)$ are $n$ elements.

Step 4: By normalization, the normalized weight vectors are

$$
W=\left(d\left(A_{1}\right), d\left(A_{2}\right), \ldots \ldots \ldots, d\left(A_{n}\right)\right)^{T}
$$

where $W$ is a non-fuzzy number.

\subsection{Ranking alternatives}

For the assessment of warehouse locations, two ranking MCDM methods TOPSIS and fuzzy TOPSIS have been anticipated in this research comparatively. In this section, these two methods are explained and compared to each other with respect to the procedural basics.

\subsubsection{The TOPSIS method}

TOPSIS (Technique for Order Preference by Similarity to Ideal Solution), developed by Hwang and Yoon in 1981, is one of the MCDA/MCDM methods for resolving real-world decision problems satisfactorily. Being a simple ranking method in conception and application, it attempts to choose the best alternative that simultaneously has the shortest distance from the positive ideal solution and the farthest distance from the negative-ideal solution. The positive ideal solution is a solution that maximizes the benefit criteria and minimizes the cost criteria, whereas the negative ideal solution maximizes the cost criteria and minimizes the benefit criteria (Wang \& Chang, 2007; Wang \& Elhag, 2006; Wang \& Lee, 2007). Actually the positive ideal solution is composed of all best values attainable of criteria, whereas the negative ideal solution consists of all worst values attainable of criteria. TOPSIS provides a cardinal ranking of alternatives using attribute information (Chen \& Hwang, 1992; Yoon \& Hwang, 1995). In TOPSIS method, precise scores that each alternative receives from all the criteria are used in the formation of a decision matrix and normalized decision matrix. By taking into consideration the rates of all attributes, positive and negative ideal solutions are found. By comparing the distance coefficient of each alternative, the preference order of the alternatives is determined.

The stepwise procedure of Hwang \& Yoon (1981) for implementing TOPSIS is presented as follows:

Step 1: Construct normalized decision matrix

$$
r_{i j}=\frac{x_{i j}}{\sqrt{\sum_{j=1}^{J} x_{i j}^{2}}}, j=1,2,3, \ldots \ldots \ldots . ., J ; i=1,2,3, \ldots \ldots \ldots ., n
$$

Where $x_{i j}$ and $r_{i j}$ are original and normalized score of decision matrix respectively.

Step 2: Construct the weighted normalized decision matrix.

$$
v_{i j}=w_{j} * r_{i j}, j=1,2,3, \ldots \ldots . ., J, i=1,2,3, \ldots \ldots . ., n
$$

Where $w_{j}$ is the weight for $j$ criterion.

Step 3: Determined the positive ideal solution (PIS) and negative ideal solution (NIS). 


$$
A^{*}=\left\{v_{1}^{*}, v_{2}^{*}, \ldots \ldots ., v_{n}^{*}\right\} \text { maximum values }
$$

Where $v_{i}^{*}=\left\{\max \left(v_{i j}\right)\right.$ if $j \in J ; \min \left(v_{i j}\right)$ if $\left.j \in J^{-}\right\}$.

$$
A^{-}=\left\{v_{1}^{-}, v_{2}^{-}, \ldots \ldots ., v_{n}^{-}\right\} \text {min imum values }
$$

Where $v^{-}=\left\{\min \left(v_{i j}\right)\right.$ if $j \in J ; \max \left(v_{i j}\right)$ if $\left.j \in J^{-}\right\}$.

Step 4: Calculate the separation measures of each alternative from PIS and NIS.

$$
\begin{aligned}
& d_{i}^{*}=\sqrt{\sum_{j=1}^{n}\left(v_{i j}-v_{j}^{*}\right)^{2}}, j=1,2, \ldots \ldots . ., J \\
& d_{i}^{-}=\sqrt{\sum_{j=1}^{n}\left(v_{i j}-v_{j}^{-}\right)^{2}}, i=1,2, \ldots \ldots . ., J
\end{aligned}
$$

Step 5: Calculate the relative closeness coefficient to the ideal solution of each alternative.

$$
C C_{i}=\frac{d_{i}^{-}}{d_{i}^{*}+d_{i}^{-}}
$$

Step 6: By comparing $\mathrm{CC}_{\mathrm{i}}$ values, the ranking of the alternatives are determined.

\subsubsection{The fuzzy TOPSIS method}

The fuzzy TOPSIS (Technique for Order Performance by Similarity to Ideal Solution) method, which is one of the well-known ranking methods for MCDM, is a practical method that matches human thinking in an actual environment. In order to deal problems with vague information, the foundation was established by Chen \& Hwang (1992). This method focuses on ranking and selecting from a set of alternatives by assigning the relative importance of attributes using fuzzy numbers instead of precise numbers. That's why this method seems to be suitable in group decision making problem in a fuzzy environment. In the fuzzy TOPSIS method, linguistic scores that each alternative receives from all the criteria are used in the formation of a fuzzy decision matrix and normalized fuzzy decision matrix. By taking into consideration the rates of all attributes, fuzzy positive and fuzzy negative ideal solutions are found. By comparing the distance coefficient of each alternative, the preference order of the alternatives is determined.

The algorithm of the fuzzy TOPSIS method has mainly nine steps given in the following (Ashtiani et al., 2009):

Step 1: Assignment of ratings to the criteria and the alternatives.

Let us assume there are $\mathrm{J}$ possible candidates called $A=\left\{A_{1}, A_{2}, A_{3}, \ldots \ldots \ldots, A_{j}\right\}$ which are to be evaluated against $\mathrm{n}$ criteria $C=\left\{C_{1}, C_{2}, C_{3}, \ldots \ldots \ldots, C_{j}\right\}$. The importance weights are denoted by $w_{i}\{i=1,2, \ldots \ldots \ldots, m\}$. The fuzzy ratings $\&$ importance weight of the $k^{t h}$ decision 
maker $D_{k}\{k=1,2, \ldots \ldots \ldots, K\}$ for each alternative $\left.A_{j}\{j=1,2, \ldots \ldots \ldots, n\}\right)$ with respect to criteria $C_{i}\{i=1,2, \ldots \ldots, m\}$ are denoted by $x_{i j}{ }^{k}=\left(a_{i j}{ }^{k}, b_{i j}{ }^{k}, c_{i j}{ }^{k}\right)$ and $w_{j}{ }^{k}=$ $\left(w_{j 1}{ }^{k}, w_{j 2}{ }^{k}, w_{j 3}{ }^{k}\right)$ where $\{i=1,2, \ldots, m ; j=1,2, \ldots ., n ; k=1,2, \ldots, K\}$ with membership function $\mu_{R K}(x)$.

Step 2: Compute aggregate fuzzy ratings for the alternatives.

The aggregated fuzzy ratings $x_{i j}$ of alternatives $(i)$ with respect to each criterion $(j)$ are given by $x_{i j}=\left(a_{i j}, b_{i j}, c_{i j}\right)$ such that:

$$
a_{i j}=\min _{k}\left\{a_{i j}^{k}\right\}, \quad b_{i j}=\frac{1}{K} \sum_{k=1}^{K} b_{i j}^{k}, \quad c_{i j}=\max _{k}\left\{c_{i j}^{k}\right\}
$$

The aggregated fuzzy weights $\left(w_{i j}\right)$ of each criterion are calculate as $w_{j}{ }^{k}\left(w_{j 1}, w_{j 2}, w_{j 3}\right)$ where

$$
\boldsymbol{w}_{\boldsymbol{j} 1}=\min _{k}\left\{w_{j k 1}\right\}, \quad \boldsymbol{w}_{\boldsymbol{j} \mathbf{2}}=\frac{\mathbf{1}}{\boldsymbol{k}} \sum_{\boldsymbol{k}=\mathbf{1}}^{\boldsymbol{K}} \boldsymbol{w}_{\boldsymbol{j} \boldsymbol{k} \mathbf{2}}, \quad \boldsymbol{w}_{\boldsymbol{j} \mathbf{3}}=\max _{k}\left\{w_{j k 3}\right\}
$$

Step 3: Compute the fuzzy decision matrix.

The fuzzy decision matrix for the alternatives (D) and the criteria (W) is constructed as follows:

$$
\begin{aligned}
& D=\begin{array}{c}
A_{1} \\
A_{2} \\
\vdots \\
A_{m}
\end{array}\left[\begin{array}{cccc}
X_{11} & X_{12} & \cdots & X_{1 n} \\
X_{21} & X_{22} & \cdots & X_{2 n} \\
X_{m 1} & X_{m 2} & \cdots & X_{m n}
\end{array}\right] \\
& W=\left[w_{1}, w_{2}, \ldots . ., w_{n}\right]
\end{aligned}
$$

where $x_{\mathrm{ij}}$ and $\mathrm{w}_{\mathrm{j}}, i=1,2, \ldots, m ; j=1,2, \ldots ., n$ are linguistic variables which can be described by triangular fuzzy numbers, $x_{i j}=\left(a_{i j}, b_{i j}, c_{i j}\right)$ and $w_{j}\left(w_{j 1}, w_{j 2}, w_{j 3}\right)$.

Step 4: Normalize the fuzzy decision matrix.

The linear scale transformation is used to transform various criteria scales into a comparable scale. Thus, we have the normalized fuzzy decision matrix as:

$$
\widetilde{R}=\left[\widetilde{r}_{i j}\right] m \times n, \boldsymbol{i}=\mathbf{1}, \mathbf{2}, \ldots, \boldsymbol{m} ; \boldsymbol{j}=\mathbf{1}, \mathbf{2}, \ldots \ldots, \boldsymbol{n}
$$

where

$$
\begin{aligned}
& \widetilde{r_{l j}}=\frac{a_{i j}}{c_{j}^{*}}, \frac{b_{i j}}{c_{j}^{*}}, \frac{c_{i j}}{c_{j}^{*}} \text { and } c_{j}^{*}=\max c_{i j} \quad \text { (benefit criteria) } \\
& \widetilde{r_{l j}}=\frac{a_{j}^{-}}{c_{i j}}, \frac{a_{j}^{-}}{b_{i j}}, \frac{a_{j}^{-}}{a_{i j}} \text { and } a_{j}^{-}=\min a_{i j} \text { (cost criteria) }
\end{aligned}
$$


The above normalization method preserves the property that the ranges of normalized triangular fuzzy numbers belong to $[0,1]$.

Step 5: Compute the weighted normalized matrix.

The weighted normalized fuzzy decision matrix $\widetilde{V}$ is computed by multiplying the weights $\widetilde{w}_{J}$ of evaluation criteria with the normalized fuzzy decision matrix $\widetilde{r_{l j}}$ as:

$$
\tilde{V}=\left[\tilde{v}_{i j}\right] m \times n, \boldsymbol{i}=\mathbf{1}, \mathbf{2}, \ldots, \boldsymbol{m} ; \boldsymbol{j}=\mathbf{1}, \mathbf{2}, \ldots ., \boldsymbol{n} \text { where } \tilde{v}_{i j}=\tilde{r}_{i j}(.) \tilde{w}_{j}
$$

Step 6: Identify the fuzzy positive ideal solution (FPIS) and fuzzy negative ideal solution (FNIS). The FPIS and FNIS of the alternatives are computed as follows:

$$
\begin{aligned}
& A^{*}=\left\{v_{1}^{*}, v_{2}^{*}, \ldots \ldots, v_{n}^{*}\right\}, \text { where } v_{j}^{*}=\{1,1,1\}, j=1,2, \ldots, n \\
& A^{-}=\left\{v_{1}^{-}, v_{2}^{-}, \ldots \ldots, v_{n}^{-}\right\}, \text {where } v_{j}^{-}=\{0,0,0\}, j=1,2, \ldots, n
\end{aligned}
$$

Step 7: Compute the distance of each alternative from FPIS and FNIS.

The distance $\left(d_{i}^{*}, d_{i}^{-}\right)$of each alternative $i=1,2, \ldots, m$ from the FPIS and the FNIS is computed as follows:

$$
\begin{aligned}
& d_{i}^{*}=\sum_{j=1}^{n} d_{v}\left(\widetilde{v_{\imath \jmath}}, \widetilde{v}_{j}^{*}\right), i=1,2 \ldots, m ; j=1,2, \ldots, n \\
& d_{i}^{-}=\sum_{j=1}^{n} d_{v}\left(\widetilde{v_{\imath \jmath}}, \widetilde{v}_{j}^{-}\right), i=1,2 \ldots, m ; j=1,2, \ldots, n
\end{aligned}
$$

Step 8: The closeness coefficient $\left(C C_{i}\right)$ of each alternative is calculated as follows:

$$
C C_{i}=\frac{d_{i}^{-}}{d_{i}^{*}+d_{i}^{-}}
$$

Step 9: By comparing $C C_{i}$ values, the ranking of the alternatives are determined.

\subsubsection{Comparison of the two ranking methods}

TOPSIS method is simple and easy to implement but it becomes difficult for a decision-maker to assign a precise performance rating to an alternative (Chaghooshi et al., 2013). The TOPSIS method becomes erroneous especially in realistic problems where personal opinions and convictions are expressed in precise intervals. The merit of using a fuzzy approach is to assign the relative importance of attributes using fuzzy numbers instead of precise numbers. This method is particularly suitable for solving the group decision-making problem under fuzzy environment as it uses a fuzzy linguistic value as a substitute for the directly given crisp value in the grade assessment. The linguistic expressions of fuzzy theory are considered as natural representations of preferences/judgments (Wang et al., 2009).

\section{Proposed framework with example}

A comparison of five existing warehouse locations of the renowned company in Bangladesh serves to 
validate the model by testing the propositions that were developed. To preserve confidentiality, the name of the company has been kept undisclosed and the five locations are referenced as $A_{1}, A_{2}, A_{3}, A_{4}$ and $A_{5}$. The Company desires to decide which location among the five alternatives a warehouse should be opened based on its vision and strategy. First of all, the evaluation criteria for the selection decision were taken from the studies of Min and Melachrinoudis, Alberto and MacCarthy and Atthrirawong, Demirel et al. and Dogan. The hierarchical structure of the criteria adopted in this study is portrayed in Fig. 4. According to Fig. 4, the hierarchy structure comprises of four levels: at the highest level of the hierarchy, the goal of the problem labeled as the selection of warehouse location is situated, in the second level, 5 aspects/main criteria including responsiveness, transportation conditions, cost related factors, location properties and favorable labor climate are considered for achieving the ultimate goal while in the third level, the sub-criteria of each main-criterion are listed, and five warehouse locations are in the last level.

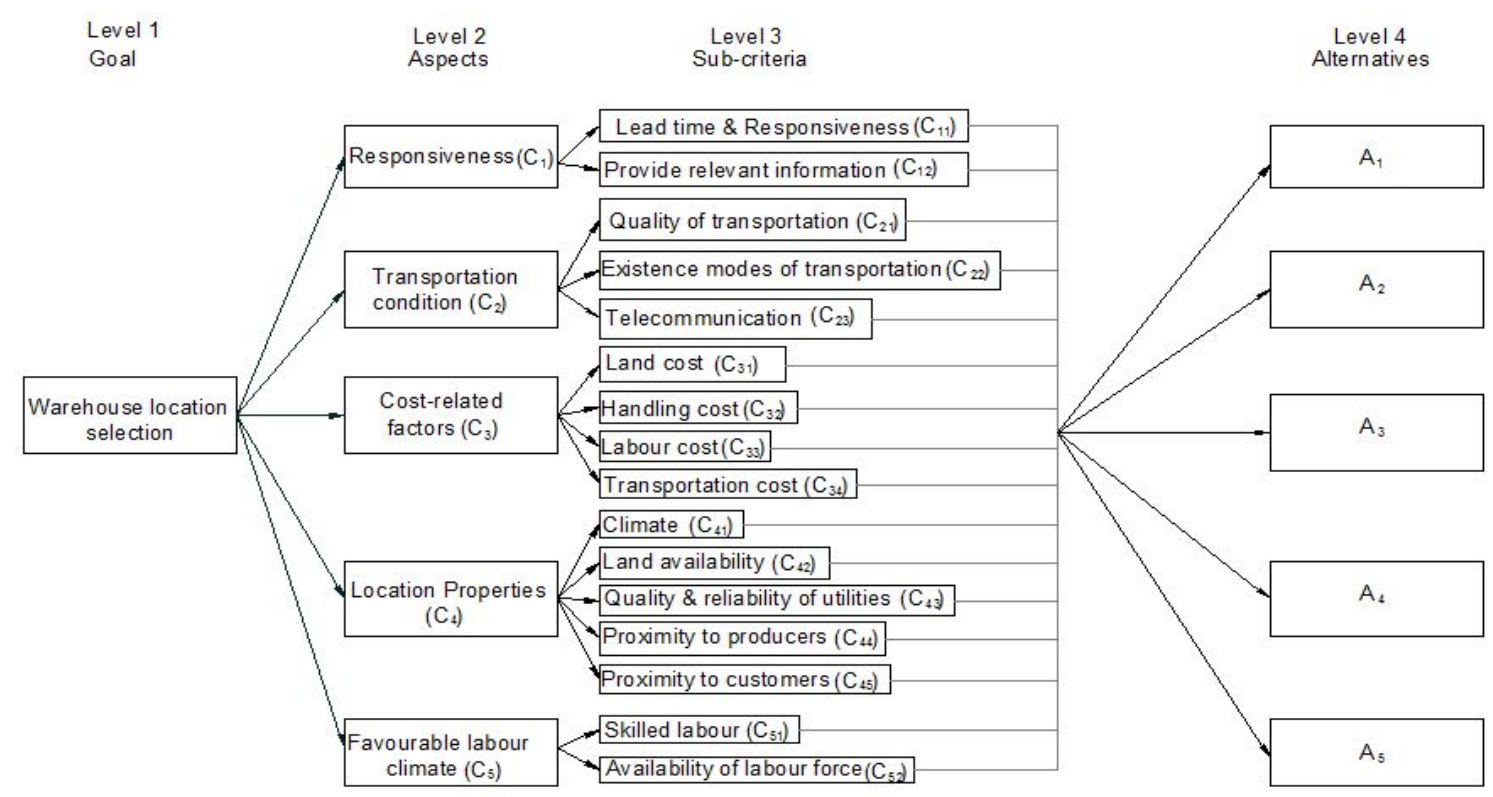

Fig. 4. The hierarchy structure of warehouse location selection

The weights of the main criteria considering the decision makers' subjective judgments are estimated by using FAHP. In order to reduce the uncertainty and vagueness in the decision process, the pair-wise comparison scores have been proposed by three decision makers for determining the weights of the main criteria and the sub-criteria by using Saaty's 1-9 scale (Chen, 2004). Then, an aggregated fuzzy pair-wise comparison matrix is constructed by integrating three decision makers' grades by using Eq. (18) (Chen et al., 2006). Fuzzy pair-wise comparison matrix for the main-criteria (Table 1) and the calculation of the weights are given as follows.

\section{Table 1}

Aggregated fuzzy pair-wise comparison matrix

\begin{tabular}{cccccc}
\hline & $C_{1}$ & $C_{2}$ & $C_{3}$ & $C_{4}$ & $C_{5}$ \\
\hline$C_{1}$ & $(1,1,1)$ & $(0.143,1.83,5)$ & $(3,4.33,5)$ & $(0.14,1.11,3)$ & $(7,7.67,9)$ \\
$C_{2}$ & $(0.2,3.4,7)$ & $(1,1,1)$ & $(0.2,4.07,7)$ & $(0.2,4.07,7)$ & $(1,5.67,9)$ \\
$C_{3}$ & $(0.2,0.24,0.33)$ & $(0.14,1.78,5)$ & $(1,1,1)$ & $(0.14,2.45,7)$ & $(0.2,3.4,5)$ \\
$C_{4}$ & $(0.33,4.11,7)$ & $(0.14,1.78,5)$ & $0.14,4.05,7$ & $(1,1,1)$ & $(5,6.33,7)$ \\
$C_{5}$ & $(0.11,0.13,0.14)$ & $(0.11,0.42,1)$ & $(0.20,2.6,5)$ & $(0.14,0.14,0.2)$ & $(1,1,1)$ \\
\hline
\end{tabular}

The values of fuzzy synthetic extent are calculated by using Eq. (1). 
$S_{c_{1}}=(11.29,15.94,23) \otimes(1 / 106.86,1 / 64.58,1 / 23.76)=(0.11,0.25,0.97)$

$S_{c_{2}}=(2.60,18.20,31) \otimes(1 / 106.86,1 / 64.58,1 / 23.76)=(0.02,0.28,1.30)$

$S_{c_{3}}=(1.69,8.87,18.33) \otimes(1 / 106.86,1 / 64.58,1 / 23.76)=(0.02,0.14,0.77)$

$S_{c_{4}}=(6.62,17.27,27) \otimes(1 / 106.86,1 / 64.58,1 / 23.76)=(0.06,0.27,1.14)$

$S_{c_{5}}=(1.57,4.29,7.34) \otimes(1 / 106.86,1 / 64.58,1 / 23.76)=(0.01,0.07,0.31)$

The degree of possibility of supremacy of each criterion over another denoting by $V\left(S_{c_{i}} \geq\right.$ $S_{c_{j}}$ where $\left.i=1,2,3,4,5 ; j=1,2,3,4,5\right)$. The obtained synthetic values are compared by using Eq. (7) and the following results are obtained:

$$
\begin{array}{llll}
\boldsymbol{V}\left(\boldsymbol{S}_{\boldsymbol{C}_{1}} \geq \boldsymbol{S}_{\boldsymbol{C}_{2}}\right)=0.96 & \boldsymbol{V}\left(\boldsymbol{S}_{\boldsymbol{C}_{1}} \geq \boldsymbol{S}_{\boldsymbol{C}_{3}}\right)=1.00 & \boldsymbol{V}\left(\boldsymbol{S}_{\boldsymbol{C}_{1}} \geq \boldsymbol{S}_{\boldsymbol{C}_{4}}\right)=0.978 & \boldsymbol{V}\left(\boldsymbol{S}_{\boldsymbol{C}_{1}} \geq \boldsymbol{S}_{\boldsymbol{C}_{5}}\right)=1.00 \\
\boldsymbol{V}\left(\boldsymbol{S}_{\boldsymbol{C}_{2}} \geq \boldsymbol{S}_{\boldsymbol{C}_{1}}\right)=1.00 & \boldsymbol{V}\left(\boldsymbol{S}_{\boldsymbol{C}_{2}} \geq \boldsymbol{S}_{\boldsymbol{C}_{3}}\right)=1.00 & \boldsymbol{V}\left(\boldsymbol{S}_{\boldsymbol{C}_{2}} \geq \boldsymbol{S}_{\boldsymbol{C}_{4}}\right)=1.00 & \boldsymbol{V}\left(\boldsymbol{S}_{\boldsymbol{C}_{2}} \geq \boldsymbol{S}_{\boldsymbol{C}_{5}}\right)=1.00 \\
\boldsymbol{V}\left(\boldsymbol{S}_{\boldsymbol{C}_{3}} \geq \boldsymbol{S}_{\boldsymbol{C}_{1}}\right)=\mathbf{0 . 8 6} & \boldsymbol{V}\left(\boldsymbol{S}_{\boldsymbol{C}_{3}} \geq \boldsymbol{S}_{\boldsymbol{C}_{2}}\right)=0.84 & \boldsymbol{V}\left(\boldsymbol{S}_{\boldsymbol{C}_{3}} \geq \boldsymbol{S}_{\boldsymbol{C}_{4}}\right)=0.85 & \boldsymbol{V}\left(\boldsymbol{S}_{\boldsymbol{C}_{3}} \geq \boldsymbol{S}_{\boldsymbol{C}_{5}}\right)=1.00 \\
\boldsymbol{V}\left(\boldsymbol{S}_{\boldsymbol{C}_{4}} \geq \boldsymbol{S}_{\boldsymbol{C}_{1}}\right)=1.00 & \boldsymbol{V}\left(\boldsymbol{S}_{\boldsymbol{C}_{4}} \geq \boldsymbol{S}_{\boldsymbol{C}_{2}}\right)=0.99 & \boldsymbol{V}\left(\boldsymbol{S}_{\boldsymbol{C}_{4}} \geq \boldsymbol{S}_{\boldsymbol{C}_{3}}\right)=1.00 & \boldsymbol{V}\left(\boldsymbol{S}_{\boldsymbol{C}_{4}} \geq \boldsymbol{S}_{\boldsymbol{C}_{5}}\right)=1.00 \\
\boldsymbol{V}\left(\boldsymbol{S}_{\boldsymbol{C}_{5}} \geq \boldsymbol{S}_{\boldsymbol{C}_{1}}\right)=0.53 & \boldsymbol{V}\left(\boldsymbol{S}_{\boldsymbol{C}_{5}} \geq \boldsymbol{S}_{\boldsymbol{C}_{2}}\right)=0.57 & \boldsymbol{V}\left(\boldsymbol{S}_{\boldsymbol{C}_{5}} \geq \boldsymbol{S}_{\boldsymbol{C}_{3}}\right)=0.81 & \boldsymbol{V}\left(\boldsymbol{S}_{\boldsymbol{C}_{5}} \geq \boldsymbol{S}_{\boldsymbol{C}_{4}}\right)=0.53
\end{array}
$$

Then the priority weights are calculated by using Eq. (8):

$$
\begin{aligned}
d^{\prime}\left(C_{1}\right)=\min (0.96,1.00,0.978,1.00)=0.96 & d^{\prime}\left(C_{4}\right)=\min (1.00,0.99,1.00,1.00)=0.99 \\
d^{\prime}\left(C_{2}\right)=\min (1.00,1.00,1.00,1.00)=1.00 & \\
d^{\prime}\left(C_{3}\right)=\min (0.86,0.84,0.85,1.00)=0.84 & d^{\prime}\left(C_{5}\right)=\min (0.53,0.57,0.81,0.53)=0.53
\end{aligned}
$$

The weight vector forms $W^{\prime}=(0.96,1.00,0.84,0.99,0.53)$. After the normalization, weight vector of the main criteria $W^{\prime}=(0.96,1.00,0.84,0.99,0.53)$ is transformed into the normalized weight vector with respect to the main-criteria as $W=(0.2232,0.2315,0.1940,0.2286,0.1227)$. The normalized weight vector respect to main goal is portrayed in Fig. 5.

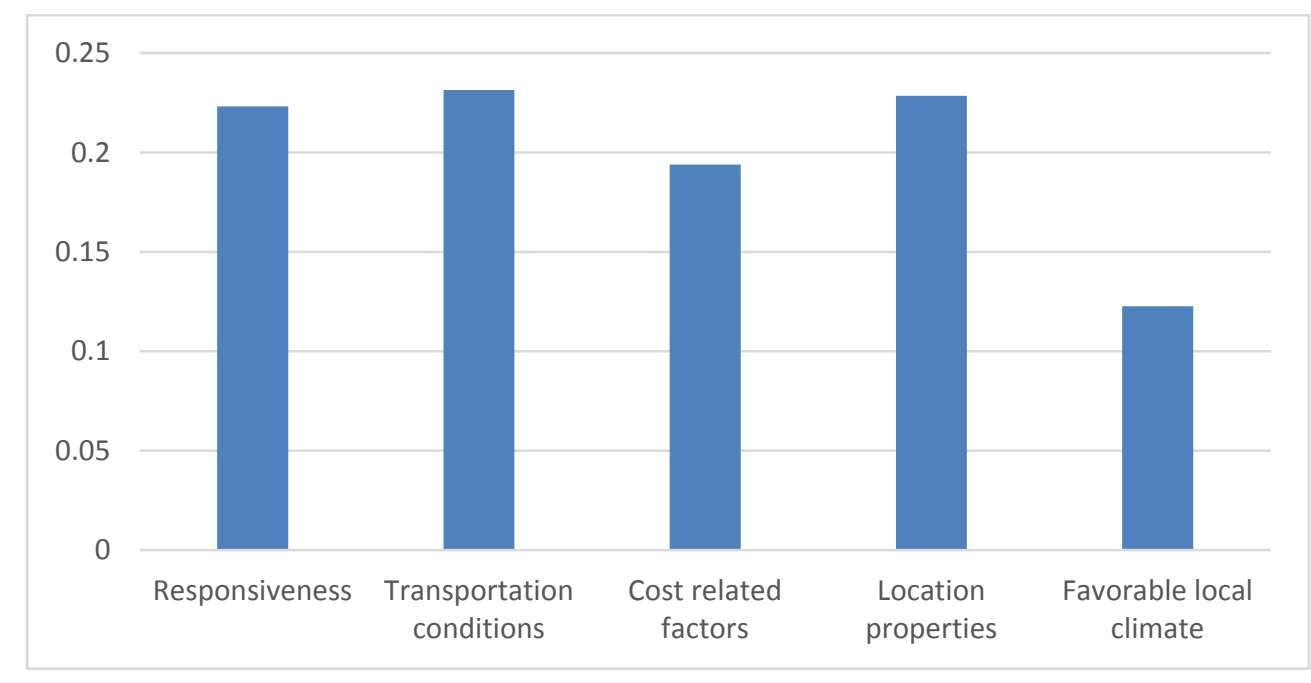

Fig. 5. Normalized weights of main criteria

According to Fig. 5, the most important criteria having priority of 0.2315 is “Transportation Condition" in the decision makers' subjective judgments which are followed by the others. The same computational ways are anticipated to determine the weights of the sub-criteria $\left(\widetilde{w}_{J}\right)$ which are presented in Table 2. 
Table 2

Weights of sub-criteria

\begin{tabular}{cccc}
\hline Sub-criteria & Weight & Sub-criteria & Weight \\
\hline$C_{11}$ & 0.5278 & $C_{34}$ & 0.2770 \\
$C_{12}$ & 0.4722 & $C_{41}$ & 0.1361 \\
$C_{21}$ & 0.4505 & $C_{42}$ & 0.1005 \\
$C_{22}$ & 0.3019 & $C_{43}$ & 0.1688 \\
$C_{23}$ & 0.2477 & $C_{44}$ & 0.3035 \\
$C_{31}$ & 0.2122 & $C_{45}$ & 0.2910 \\
$C_{32}$ & 0.2658 & $C_{51}$ & 0.5278 \\
$C_{33}$ & 0.2450 & $C_{52}$ & 0.4722 \\
\hline
\end{tabular}

As indicated before, two MCDM approaches, TOPSIS and fuzzy TOPSIS methods, are used to rank the potential alternatives considering the weights of all criteria which are obtained by fuzzy AHP. In the first step of the algorithms, a fuzzy decision matrix is developed by transforming fuzzy linguistics variables into triangular fuzzy numbers in fuzzy TOPSIS method while in TOPSIS method, a decision matrix is constructed using numerical values. Linguistics assessment of five alternatives using linguistics variables and decision matrix are shown in Tables $3 \& 4$ respectively.

Table 3

Decision matrix for fuzzy TOPSIS method using fuzzy linguistics variables

\begin{tabular}{|c|c|c|c|c|c|c|c|c|c|c|c|c|c|c|c|}
\hline & \multicolumn{3}{|l|}{$\overline{A_{1}}$} & \multicolumn{3}{|l|}{$A_{2}$} & \multicolumn{3}{|l|}{$A_{3}$} & \multicolumn{3}{|l|}{$\overline{A_{4}}$} & \multicolumn{3}{|l|}{$\overline{A_{5}}$} \\
\hline & $D_{1}$ & $D_{2}$ & $D_{3}$ & $D_{1}$ & $D_{2}$ & $D_{3}$ & $D_{1}$ & $D_{2}$ & $D_{3}$ & $D_{1}$ & $D_{2}$ & $D_{3}$ & $D_{1}$ & $D_{2}$ & $D_{3}$ \\
\hline$C_{11}$ & $V G$ & $V G$ & $G$ & $G$ & $M G$ & $M G$ & $M G$ & $F$ & $M G$ & $M G$ & $F$ & $M G$ & $G$ & $G$ & $M G$ \\
\hline$C_{12}$ & $G$ & $G$ & $M G$ & $F$ & $M G$ & $F$ & $M G$ & $F$ & $G$ & $F$ & $G$ & $G$ & $V G$ & $G$ & $F$ \\
\hline$C_{21}$ & $M G$ & $G$ & $G$ & $M G$ & $M G$ & $M G$ & $M G$ & $F$ & $M G$ & $M G$ & $F$ & $M G$ & $M G$ & $M G$ & $F$ \\
\hline$C_{22}$ & $G$ & $V G$ & $G$ & $M G$ & $M G$ & $M G$ & $M G$ & $F$ & $M G$ & $M G$ & $F$ & $M G$ & $M G$ & $G$ & $M G$ \\
\hline$C_{23}$ & $M G$ & $F$ & $M G$ & $F$ & $F$ & $M G$ & $F$ & $F$ & $F$ & $F$ & $F$ & $F$ & $F$ & $F$ & $M G$ \\
\hline$C_{31}$ & $M P$ & $F$ & $M P$ & $F$ & $F$ & $M P$ & $M P$ & $M P$ & $F$ & $M P$ & $M P$ & $F$ & $M P$ & $F$ & $F$ \\
\hline$C_{32}$ & $G$ & $M G$ & $M G$ & $M G$ & $F$ & $F$ & $M G$ & $F$ & $F$ & $M G$ & $M G$ & $F$ & $M G$ & $M G$ & $F$ \\
\hline$C_{33}$ & $G$ & $M G$ & $G$ & $F$ & $F$ & $M G$ & $F$ & $F$ & $M G$ & $F$ & $F$ & $M G$ & $M G$ & $M G$ & $M G$ \\
\hline$C_{34}$ & $G$ & $M G$ & $M G$ & $F$ & $M G$ & $F$ & $F$ & $F$ & $F$ & $F$ & $M G$ & $F$ & $M G$ & $M G$ & $M G$ \\
\hline$C_{41}$ & $G$ & $M G$ & $G$ & $M G$ & $M G$ & $G$ & $M G$ & $M G$ & $M G$ & $F$ & $M G$ & $M G$ & $M G$ & $M G$ & $M G$ \\
\hline$C_{42}$ & $G$ & $G$ & $G$ & $F$ & $F$ & $F$ & $F$ & $M G$ & $M G$ & $M G$ & $F$ & $M G$ & $M G$ & $M G$ & $M G$ \\
\hline$C_{43}$ & $G$ & $M G$ & $M G$ & $M G$ & $M G$ & $M G$ & $F$ & $F$ & $M G$ & $M G$ & $M G$ & $M G$ & $M G$ & $M G$ & $M G$ \\
\hline$C_{44}$ & $V G$ & $V G$ & $G$ & $G$ & $M G$ & $M G$ & $M G$ & $F$ & $M G$ & $M G$ & $F$ & $M G$ & $M G$ & $F$ & $M G$ \\
\hline$C_{45}$ & $G$ & $M G$ & $G$ & $M G$ & $M G$ & $M G$ & $M G$ & $F$ & $M G$ & $M G$ & $F$ & $M G$ & $G$ & $G$ & $F$ \\
\hline$C_{51}$ & $G$ & $G$ & $M G$ & $M G$ & $M G$ & $F$ & $M G$ & $F$ & $F$ & $M G$ & $F$ & $F$ & $M G$ & $M G$ & $F$ \\
\hline$C_{52}$ & $G$ & $G$ & $M G$ & $M G$ & $M G$ & $M G$ & $F$ & $F$ & $F$ & $F$ & $M G$ & $F$ & $M G$ & $M G$ & $M G$ \\
\hline
\end{tabular}

Table 4

Decision matrix for TOPSIS method

\begin{tabular}{|c|c|c|c|c|c|c|c|c|c|c|c|c|c|c|c|}
\hline & \multicolumn{3}{|c|}{$A_{1}$} & \multicolumn{3}{|c|}{$A_{2}$} & \multicolumn{3}{|c|}{$A_{3}$} & \multicolumn{3}{|c|}{$A_{4}$} & \multicolumn{3}{|c|}{$A_{5}$} \\
\hline & $D_{1}$ & $D_{2}$ & $D_{3}$ & $D_{1}$ & $D_{2}$ & $D_{3}$ & $D_{1}$ & $D_{2}$ & $D_{3}$ & $D_{1}$ & $D_{2}$ & $D_{3}$ & $D_{1}$ & $D_{2}$ & $D_{3}$ \\
\hline$C_{11}$ & 9 & 9 & 7 & 7 & 8 & 8 & 8 & 6 & 8 & 8 & 6 & 8 & 7 & 7 & 8 \\
\hline$C_{12}$ & 7 & 7 & 8 & 6 & 8 & 6 & 8 & 6 & 7 & 6 & 7 & 7 & 9 & 7 & 6 \\
\hline$C_{21}$ & 8 & 7 & 7 & 8 & 8 & 8 & 8 & 6 & 8 & 8 & 6 & 8 & 8 & 6 & 8 \\
\hline$C_{22}$ & 7 & 9 & 7 & 8 & 8 & 8 & 8 & 6 & 8 & 8 & 6 & 8 & 8 & 7 & 8 \\
\hline$C_{23}$ & 8 & 6 & 8 & 6 & 6 & 8 & 6 & 6 & 6 & 6 & 6 & 6 & 6 & 6 & 8 \\
\hline$C_{31}$ & 5 & 6 & 5 & 6 & 6 & 5 & 5 & 5 & 6 & 5 & 5 & 6 & 5 & 5 & 6 \\
\hline$C_{32}$ & 7 & 8 & 8 & 8 & 6 & 6 & 8 & 6 & 6 & 8 & 8 & 6 & 8 & 8 & 6 \\
\hline$C_{33}$ & 7 & 8 & 7 & 6 & 6 & 8 & 6 & 6 & 8 & 6 & 6 & 8 & 8 & 8 & 8 \\
\hline$C_{34}$ & 7 & 8 & 8 & 6 & 8 & 6 & 6 & 6 & 6 & 6 & 8 & 6 & 8 & 8 & 8 \\
\hline$C_{41}$ & 7 & 8 & 7 & 8 & 8 & 7 & 8 & 8 & 8 & 6 & 8 & 8 & 8 & 8 & 8 \\
\hline$C_{42}$ & 7 & 7 & 7 & 6 & 6 & 6 & 6 & 8 & 8 & 8 & 6 & 8 & 8 & 8 & 8 \\
\hline$C_{43}$ & 7 & 8 & 8 & 8 & 8 & 8 & 6 & 6 & 8 & 8 & 8 & 8 & 8 & 8 & 8 \\
\hline$C_{44}$ & 9 & 9 & 7 & 7 & 8 & 8 & 8 & 6 & 8 & 8 & 6 & 8 & 8 & 6 & 8 \\
\hline$C_{45}$ & 7 & 8 & 7 & 8 & 8 & 8 & 8 & 6 & 8 & 8 & 6 & 8 & 7 & 7 & 6 \\
\hline$C_{51}$ & 7 & 7 & 8 & 8 & 8 & 6 & 8 & 6 & 6 & 8 & 6 & 6 & 8 & 8 & 6 \\
\hline$C_{52}$ & 7 & 7 & 8 & 8 & 8 & 8 & 6 & 6 & 6 & 6 & 8 & 6 & 8 & 8 & 8 \\
\hline
\end{tabular}


Then, the aggregated values of each sub-criterion are calculated by using Eqs. (18) for fuzzy TOPSIS method and average technique in TOPSIS method as shown in Table 5.

Table 5

Aggregated decision matrix of TOPSIS \& FTOPSIS methods

\begin{tabular}{|c|c|c|c|c|c|c|c|c|c|c|}
\hline \multicolumn{6}{|c|}{ TOPSIS } & \multicolumn{5}{|c|}{ FTOPSIS } \\
\hline & $A_{1}$ & $A_{2}$ & $A_{3}$ & $A_{4}$ & $A_{5}$ & $A_{1}$ & $A_{2}$ & $A_{3}$ & $A_{4}$ & $A_{5}$ \\
\hline$C_{11}$ & 8.33 & 7.67 & 7.33 & 7.33 & 7.33 & $(5,7.67,9)$ & $(5,6.33,7)$ & $(3,5.67,7)$ & $(3,5,67,7)$ & $(5,5.67,7)$ \\
\hline$C_{12}$ & 7.33 & 6.67 & 7.00 & 6.67 & 7.33 & $(5,5.67,7)$ & $(3,4.33,7)$ & $(3,5,7)$ & $(3,4.33,5)$ & $(3,5.67,9)$ \\
\hline$C_{21}$ & 7.33 & 8.00 & 7.33 & 7.33 & 7.33 & $(5,5.67,7)$ & $(7,7,7)$ & $(3,5.67,7)$ & $(3,5.67,7)$ & $(3,5.67,7)$ \\
\hline$C_{22}$ & 7.67 & 8.00 & 7.33 & 7.33 & 7.67 & $(5,7.67,9)$ & $(7,7,7)$ & $(3,5.67,7)$ & $(3,5.67,7)$ & $(5,6.33,7)$ \\
\hline$C_{23}$ & 7.33 & 6.67 & 6.00 & 6.00 & 6.67 & $(3,5.67,7)$ & $(3,4.33,7)$ & $(3,3,3)$ & $(3,3,3)$ & $(3,4.33,7)$ \\
\hline$C_{31}$ & 5.33 & 5.67 & 5.33 & 5.33 & 5.67 & $(1,1.67,3)$ & $(1,2.33,3)$ & $(1,1.67,3)$ & $(1,1.67,3)$ & $(1,2.33,3)$ \\
\hline$C_{32}$ & 7.67 & 6.67 & 6.67 & 7.33 & 7.33 & $(5,6.33,7)$ & $(3,4.33,7)$ & $(3,4.33,7)$ & $(3,5.67,7)$ & $(3,5.67,7)$ \\
\hline$C_{33}$ & 7.33 & 6.67 & 6.67 & 6.67 & 8.00 & $(5,5.67,7)$ & $(3,4.33,7)$ & $(3,4.33,7)$ & $(3,4.33,7)$ & $(7,7,7)$ \\
\hline$C_{34}$ & 7.67 & 6.67 & 6.00 & 6.67 & 8.00 & $(5,6.33,7)$ & $(3,4.33,7)$ & $(3,3,3)$ & $(3,4.33,7)$ & $(7,7,7)$ \\
\hline$C_{41}$ & 7.33 & 7.67 & 8.00 & 7.33 & 8.00 & $(5,5.67,7)$ & $(5,6.33,7)$ & $(7,7,7)$ & $(3,5.67,7)$ & $(7,7,7)$ \\
\hline$C_{42}$ & 7.00 & 6.00 & 7.33 & 7.33 & 8.00 & $(5,5,5)$ & $(3,3,3)$ & $(3,5.67,7)$ & $(3,5.67,7)$ & $(7,7,7)$ \\
\hline$C_{43}$ & 7.67 & 8.00 & 6.67 & 8.00 & 8.00 & $(5,6.33,7)$ & $(7,7,7)$ & $(3,4.33,7)$ & $(7,7,7)$ & $(7,7,7)$ \\
\hline$C_{44}$ & 8.33 & 7.67 & 7.33 & 7.33 & 7.33 & $(5,7.67,9)$ & $(5,6.33,7)$ & $(3,5.67,7)$ & $(3,5.67,7)$ & $(3,5,7)$ \\
\hline$C_{45}$ & 7.33 & 8.00 & 7.33 & 7.33 & 6.67 & $(5,5.67,7)$ & $(7,7,7)$ & $(3,5.67,7)$ & $(3,5.67,7)$ & $(3,4.33,5)$ \\
\hline$C_{51}$ & 7.33 & 7.33 & 6.67 & 6.67 & 7.33 & $(5,5.67,7)$ & $(3,5.67,7)$ & $(3,4.33,7)$ & $(3,4.33,7)$ & $(3,5.67,7)$ \\
\hline$C_{52}$ & 7.33 & 8.00 & 6.00 & 6.67 & 8.00 & $(5,5.67,7)$ & $(7,7,7)$ & $(3,3,3)$ & $(3,4.33,7)$ & $(7,7,7)$ \\
\hline
\end{tabular}

After calculating the aggregated values of the sub-criteria, eligible locations are ranked by using TOPSIS and fuzzy TOPSIS methods. These aggregated values are the main input for both methods. Normalization of these values is made through Eqs. (11), (22), (23) \& (24). Lately, fuzzy weighted normalized decision matrix is formed by multiplying each of the normalized fuzzy decision matrix elements with their weights. While the positive and negative ideal solution are determined by taking the maximum and minimum values for each criterion in the TOPSIS method, the positive and negative ideal solution are calculated by using Eqs. (26) \& (27) in the fuzzy TOPSIS method. Then the distance of each warehouse location from PIS $\left(A^{*}\right)$ and NIS $\left(A^{-}\right)$with respect to each criterion are calculated like in Eqs. (15), (16), (28) \& (29). Afterwards the closeness coefficients $\left(C C_{i}\right)$ of five alternatives are calculated with Eq. (30) and the ranking is done in a decreasing order. Calculation steps of the TOPSIS method are given in Table 6.

Table 6

Calculation steps of the TOPSIS method for the location selection.

\begin{tabular}{|c|c|c|c|c|c|c|c|}
\hline & \multicolumn{5}{|c|}{ Weighted normalized values } & \multirow{2}{*}{$\operatorname{PIS}\left(A^{*}\right)$} & \multirow{2}{*}{$\begin{array}{l}\text { NIS } \\
\left(A^{-}\right)\end{array}$} \\
\hline & $A_{1}$ & $A_{2}$ & $A_{3}$ & $A_{4}$ & $A_{5}$ & & \\
\hline$C_{11}$ & 0.2585 & 0.2378 & 0.2275 & 0.2275 & 0.2275 & 0.2585 & 0.2275 \\
\hline$C_{12}$ & 0.2210 & 0.2009 & 0.2110 & 0.2009 & 0.2210 & 0.2210 & 0.2009 \\
\hline$C_{21}$ & 0.1977 & 0.2157 & 0.1977 & 0.1977 & 0.1977 & 0.2157 & 0.1977 \\
\hline$C_{22}$ & 0.1361 & 0.1420 & 0.1302 & 0.1302 & 0.1361 & 0.1420 & 0.1302 \\
\hline$C_{23}$ & 0.1240 & 0.1127 & 0.1014 & 0.1014 & 0.1127 & 0.1240 & 0.1014 \\
\hline$C_{31}$ & 0.0926 & 0.0983 & 0.0926 & 0.0926 & 0.0983 & 0.0983 & 0.0926 \\
\hline$C_{32}$ & 0.1276 & 0.1109 & 0.1109 & 0.1220 & 0.1220 & 0.1276 & 0.1109 \\
\hline$C_{33}$ & 0.1134 & 0.1031 & 0.1031 & 0.1031 & 0.1237 & 0.1237 & 0.1031 \\
\hline$C_{34}$ & 0.1295 & 0.1126 & 0.1013 & 0.1126 & 0.1351 & 0.1351 & 0.1013 \\
\hline$C_{41}$ & 0.1047 & 0.1095 & 0.1142 & 0.1047 & 0.1142 & 0.1142 & 0.1047 \\
\hline $\mathrm{C}_{42}$ & 0.1210 & 0.1037 & 0.1268 & 0.1268 & 0.1383 & 0.1383 & 0.1037 \\
\hline$C_{43}$ & 0.0607 & 0.0634 & 0.0528 & 0.0634 & 0.0634 & 0.0634 & 0.0528 \\
\hline$C_{44}$ & 0.0492 & 0.0453 & 0.0433 & 0.0433 & 0.0433 & 0.0492 & 0.0433 \\
\hline$C_{45}$ & 0.0754 & 0.0822 & 0.0754 & 0.0754 & 0.0685 & 0.0822 & 0.0685 \\
\hline$C_{51}$ & 0.1407 & 0.1407 & 0.1279 & 0.1279 & 0.1407 & 0.1407 & 0.1279 \\
\hline$C_{52}$ & 0.1318 & 0.1438 & 0.1078 & 0.1198 & 0.1438 & 0.1438 & 0.1078 \\
\hline$d^{*}$ & 0.0334162 & 0.0583215 & 0.075449004 & 0.0661558 & 0.0412388 & & \\
\hline$d-$ & 0.0653132 & 0.0513711 & 0.027749987 & 0.0329149 & 0.0717094 & & \\
\hline$C C_{i}$ & 0.661537 & 0.4683185 & 0.268897851 & 0.3322365 & 0.6348872 & & \\
\hline
\end{tabular}


Calculation steps of the fuzzy TOPSIS method are given Table 7.

Table 7

Calculation steps of the fuzzy TOPSIS method for the location selection

\begin{tabular}{|c|c|c|c|c|c|c|c|}
\hline & \multicolumn{5}{|c|}{ Weighted normalized values } & \multirow{2}{*}{ FPIS $\left(A^{*}\right)$} & \multirow{2}{*}{ FNIS $\left(A^{-}\right)$} \\
\hline & $A_{1}$ & $A_{2}$ & $A_{3}$ & $A_{4}$ & $A_{5}$ & & \\
\hline$C_{11}$ & $(0.29,0.45,0.53)$ & $(0.29,0.37,0.41)$ & $(0.18,0.33,0.41)$ & $(0.18,0.33,0.41)$ & $(0.29,0.33,0.41)$ & $(1,1,1)$ & $(0,0,0)$ \\
\hline$C_{12}$ & $(0.26,0.30,0.37)$ & $(0.33,0.48,0.78)$ & $(0.33,0.56,0.78)$ & $(0.16,0.30,0.47)$ & $(0.16,0.30,0.47)$ & $(1,1,1)$ & $(0,0,0)$ \\
\hline$C_{21}$ & $(0.32,0.36,0.45)$ & $(0.45,0.45,0.45)$ & $(0.19,0.36,0.45)$ & $(0.19,0.36,0.45)$ & $(0.19,0.36,0.45)$ & $(1,1,1)$ & $(0,0,0)$ \\
\hline$C_{22}$ & $(0.17,0.26,0.30)$ & $(0.23,0.23,0.23)$ & $(0.10,0.19,0.23)$ & $(0.10,0.19,0.23)$ & $(0.17,0.21,0.23)$ & $(1,1,1)$ & $(0,0,0)$ \\
\hline$C_{23}$ & $(0.11,0.20,0.25)$ & $(0.11,0.15,0.25)$ & $(0.11,0.11,0.11)$ & $(0.11,0.11,0.11)$ & $(0.11,0.15,0.25)$ & $(1,1,1)$ & $(0,0,0)$ \\
\hline$C_{31}$ & $(0.07,0.23,0.21)$ & $(0.07,0.09,0.21)$ & $(0.07,0.13,0.21)$ & $(0.07,0.13,0.21)$ & $(0.07,0.09,0.21)$ & $(1,1,1)$ & $(0,0,0)$ \\
\hline$C_{32}$ & $(0.11,0.13,0.16)$ & $(0.11,0.18,0.27)$ & $(0.11,0.18,0.27)$ & $(0.11,0.14,0.27)$ & $(0.11,0.14,0.27)$ & $(1,1,1)$ & $(0,0,0)$ \\
\hline$C_{33}$ & $(0.10,0.13,0.15)$ & $(0.10,0.17,0.24)$ & $(0.10,0.17,0.24)$ & $(0.10,0.17,0.24)$ & $(0.10,0.10,0.10)$ & $(1,1,1)$ & $(0,0,0)$ \\
\hline$C_{34}$ & $(0.12,0.13,0.17)$ & $(0.12,0.19,0.28)$ & $(0.28,0.28,0.28)$ & $(0.12,0.19,0.28)$ & $(0.12,0.12,0.12)$ & $(1,1,1)$ & $(0,0,0)$ \\
\hline$C_{41}$ & $(0.10,0.11,0.14)$ & $(0.10,0.12,0.14)$ & $(0.14,0.14,0.14)$ & $(0.06,0.11,0.14)$ & $(0.14,0.14,0.14)$ & $(1,1,1)$ & $(0,0,0)$ \\
\hline$C_{42}$ & $(0.07,0.07,0.07)$ & $(0.04,0.04,0.04)$ & $(0.04,0.08,0.10)$ & $(0.04,0.08,0.10)$ & $(0.10,0.10,0.10)$ & $(1,1,1)$ & $(0,0,0)$ \\
\hline$C_{43}$ & $(0.12,0.15,0.17)$ & $(0.17,0.17,0.17)$ & $(0.07,0.10,0.17)$ & $(0.17,0.17,0.17)$ & $(0.17,0.17,0.17)$ & $(1,1,1)$ & $(0,0,0)$ \\
\hline$C_{44}$ & $(0.17,0.26,0.30)$ & $(0.17,0.21,0.24)$ & $(0.10,0.19,0.24)$ & $(0.10,0.19,0.24)$ & $(0.10,0.17,0.24)$ & $(1,1,1)$ & $(0,0,0)$ \\
\hline$C_{45}$ & $(0.21,0.24,0.29)$ & $(0.29,0.29,0.29)$ & $(0.12,0.24,0.29)$ & $(0.12,0.24,0.29)$ & $(0.12,0.18,0.21)$ & $(1,1,1)$ & $(0,0,0)$ \\
\hline$C_{51}$ & $(0.38,0.43,0.53)$ & $(0.23,0.43,0.53)$ & $(0.23,0.33,0.53)$ & $(0.23,0.33,0.53)$ & $(0.23,0.43,0.53)$ & $(1,1,1)$ & $(0,0,0)$ \\
\hline$C_{52}$ & $(0.34,0.38,0.47)$ & $(0.47,0.47,0.47)$ & $(0.20,0.20,0.20)$ & $(0.20,0.29,0.47)$ & $(0.47,0.47,0.47)$ & $(1,1,1)$ & $(0,0,0)$ \\
\hline$d^{*}$ & 12.29035 & 12.19292 & 12.80391 & 12.8152 & 12.54792037 & & \\
\hline$d-$ & 3.806509 & 3.933572 & 3.37923 & 3.396524 & 3.613519144 & & \\
\hline$C C_{i}$ & 0.236475 & 0.24392 & 0.208812 & 0.20951 & 0.223588941 & & \\
\hline
\end{tabular}

In Table 8, locations of the warehouse are ranked with respect to both methods.

Table 8

Ranking of the warehouse location

\begin{tabular}{ccccc}
\hline Alternatives & \multicolumn{2}{c}{ TOPSIS } & \multicolumn{2}{c}{ Fuzzy TOPSIS } \\
\hline & $C C_{i}$ & Ranking & $C C_{i}$ & Ranking \\
\hline$A_{1}$ & 0.6615 & 1 & 0.2365 & 2 \\
$A_{2}$ & 0.4683 & 3 & 0.2439 & 1 \\
$A_{3}$ & 0.2689 & 5 & 0.2088 & 5 \\
$A_{4}$ & 0.3322 & 4 & 0.2095 & 4 \\
$A_{5}$ & 0.6349 & 2 & 0.2236 & 3 \\
\hline
\end{tabular}

\section{Results and discussions}

Depending on the values of closeness coefficients of five warehouse location, the best ranked alternative for the warehouse location is different with respect to both methods. While location $A_{1}$ is the best ranked company in the TOPSIS method, location $A_{2}$ is the best ranked company in the fuzzy TOPSIS method.

\section{Conclusions and future work}

Proper decision paves the way for inclusive growth and ultimate profit of a company. Therefore, taking geographical location, availability of workers, export friendly policy etc. factors into consideration, it can easily be possible that a company has empowering situations for its faster growth. Therefore, the consideration of this several criteria and sub-criteria makes the process of location selection more difficult. For that reason, this paper has presented a structured model using fuzzy analytic hierarchy process (FAHP) and fuzzy TOPSIS method as an effective tool for selecting the most desirable facility location. The Fuzzy TOPSIS method is one of the multi-criteria decision making methods which enables the decision makers to make the exact judgment for location selection from different 
alternatives. In this paper, the weights of the different criteria are derived by applying fuzzy AHP and for ranking between them two MCDM methods namely TOPSIS \& fuzzy TOPSIS methods have been used. Rather this method has enormous probability by dealing with different philosophy specially which are doubtful and vague. So, it seems that the road to success in this respect is not smooth at all and is expected to be even more challenging in the future. Therefore, in the future, it is not an option but essential to implement this method for dealing with uncertainty in a variety of multi-criteria decision making problems. The proposed method is also effective in group decision environment where it is found to be difficult to come to a moot point individually. Thus, it will also help in future researches as well. In addition to the proposed methods in this study, some other MCDM methods such as ELECTRE; PROMETHEE; MOORA and ORESTE can be used comparatively in a fuzzy environment.and the results can be compared.

\section{Acknowledgements}

The authors wish to acknowledge the support and assistance provided by the Department of Industrial and Production Engineering, Jessore University of Science and Technology, Bangladesh. The efforts of the chairman of the departments, teachers and students of Jessore Science and Technology University who collaborated in this study are also appreciated.

\section{References}

Alberto, P. (2000). The logistics of industrial location decisions: An application of the analytic hierarchy process methodology. International Journal of Logistics, 3(3), 273-289.

Anand, G., Kodali, R., \& Dhanekula, C. S. (2012). An application of analytic network process for selection of a plant location: a case study. International Journal of Services and Operations Management, 12(1), 35-66.

Ashrafzadeh, M., Rafiei, F. M., Isfahani, N. M., \& Zare, Z. (2012). Application of fuzzy TOPSIS method for the selection of Warehouse Location: A Case Study. Interdisciplinary Journal of Contemporary Research in Business, 3(9), 655-671.

Ashtiani, B., Haghighirad, F., Makui, A., \& ali Montazer, G. (2009). Extension of fuzzy TOPSIS method based on interval-valued fuzzy sets. Applied Soft Computing, 9(2), 457-461.

Badri, M. A. (1999). Combining the analytic hierarchy process and goal programming for global facility location-allocation problem. International Journal of Production Economics, 62(3), 237248.

Bozbura, F.T., \& Beskese, A. (2007). Prioritization of organizational capital measurement indicators using fuzzy AHP. International Journal of Approximate Reasoning, 44(2), 124-147.

Buckley, J. J. (1985). Fuzzy hierarchical analysis. Fuzzy Sets and Systems, 17, 233-247.

Carrera, D. A., \& Mayorga, R. V. (2008). Supply chain management: A modular fuzzy inference system approach in supplier selection for new product development. Journal of Intelligent Manufacturing, 19(1), 1-12.

Chaghooshi, A. J., Ahangari, S. S., Moradi-Moghadam, M., \& Fagheyi, M. S. A (2013). New integrated approach of linear goal programming and fuzzy TOPSIS for technology selection. New York Science Journal, 6(6).

Chan, F. T. S., \& Chung, S. H. (2004). Multi-criteria genetic optimization for distribution network problems. The International Journal of Advanced Manufacturing Technology, 24(7-8), 517-532.

Chang, D.Y. (1992). Extent analysis and synthetic decision. Optimization Techniques and Applications, 1, 352-355.

Chang, D.Y. (1996). Applications of the extent analysis method on fuzzy AHP. European Journal of Operational Research, 95(3), 649-655.

Chen, C. T., Lin, C. T., \& Huang, S. F. (2006). A fuzzy approach for supplier evaluation and selection in supply chain management. International Journal of Production Economics, 102, 289-301. 
Chen, G., \& Pham, T. T. (2001). Introduction to fuzzy, sets fuzzy, logic and fuzzy control systems. Florida: CRC Press.

Chen, H. (2004). A research based on fuzzy AHP for multi-criteria supplier selection in supply chain. Master thesis, National Taiwan University of Science and Technology, Department of Industrial Management.

Chen, S. J., \& Hwang, C. L. (1992). Fuzzy multiple attribute decision making: Methods and applications. Berlin: Springer-Verlag.

Cheng, C. H., Chen, C. T., \& Huang, S. F. (2012). Combining fuzzy integral with order weight average (OWA) method for evaluating financial performance in the semiconductor industry. African Journal of Business Management, 6(21), 6358-6368.

Csutora, R., \& Buckley, J. J. (2001). Fuzzy hierarchical analysis: the Lambda-Max method. Fuzzy sets and Systems, 120(2), 181-195.

Davoudi, M. R., \& Sheikhvand, K. (2012). An approach towards enterprise architecture analysis using AHP and fuzzy AHP. International Journal of Machine Learning and Computing, 2(1), 46-51.

Demirel, T., Demirel, N. Ç., \& Kahraman, C. (2010). Multi-criteria warehouse location selection using Choquet integral. Expert Systems with Applications, 37(5), 3943-3952.

Deng, H. (1999). Multicriteria analysis with fuzzy pair-wise comparison. International Journal of Approximate Reasoning, 21, 215-231.

Dey, B., Bairagi, B., Sarkar, B \& Sanyal, S. (2012). A MOORA based fuzzy multi-criteria decision making approach for supply chain strategy selection. International Journal of Industrial Engineering Computations, 3(4), 649-662.

Dogan, I. (2012). Analysis of facility location model using Bayesian Networks. Expert Systems with Applications, 39(1), 1092-1104.

Dursun, M., \& Karsak, E. E. (2013). A QFD-based fuzzy MCDM approach for supplier selection. Applied Mathematical Modelling, 37(8), 5864-5875.

Enea, M., \& Piazza, T. (2004). Project selection by constrained fuzzy AHP. Fuzzy Optimization and Decision Making (Vol. 3). New York: Kluwer Academic Publishers, pp. 39-62.

Ertuğrul, İ., \& Karakaşoğlu, N. (2008). Comparison of fuzzy AHP and fuzzy TOPSIS methods for facility location selection. The International Journal of Advanced Manufacturing Technology, 39(7-8), 783-795.

Farahani, R. Z., \& Asgari, N. (2007). Combination of MCDM and covering techniques in a hierarchical model for facility location: A case study. European Journal of Operational Research, 176(3), 1839-1858.

Frazelle, E. (2002). Supply Chain Strategy: The Logistics of Supply Chain Management. McGraw-Hill, New York.

Heizer, J., \& Render, B. (2001). Production and Operations Management, Sixth Edition, USA: Prentice-Hall.

Hwang, C. L., \& Yoon, K. (1981). Multiple attributes decision making methods and applications. Berlin: Springer.

Kabir, G., \& Hasin, M.A.A. (2011). Evaluation of customer oriented success factors in mobile commerce using fuzzy AHP. Journal of Industrial Engineering and Management, Article in press.

Kahraman, C., Cebeci, U., \& Ruan, D. (2004). Multi-attribute comparison of catering service companies using fuzzy AHP: the case of Turkey. International Journal of Production Economics, 87(2), 171-184.

Kahraman, C., Cebeci, U., \& Ulukan, Z. (2003). Multi-criteria supplier selection using fuzzy AHP. Logistics Information Management, 16(6), 382-394.

Kahraman, C., Ruan, D., \& Doğan, I. (2003). Fuzzy group decision-making for facility location selection. Information Sciences, 157, 135-153.

Kaufmann, A., \& Gupta, M. M. (1991). Introduction to fuzzy arithmetic: theory and applications. Arden Shakespeare.

Liang, G. S. (1999). Fuzzy MCDM based on ideal and anti-ideal concepts. European Journal of Operational Research, 112(3), 682-691. 
Liang, G. S., \& Wang, M. J. J. (1991). A fuzzy multi-criteria decision-making method for facility site selection. The International Journal of Production Research, 29(11), 2313-2330.

Lootsma, F. A. (1999). Multi-criteria decision analysis via ratio and difference judgement. Kluwer Academic Publishers.

MacCarthy, B. L., \& Atthirawong, W. (2003). Factors affecting location decisions in international operations-a Delphi study. International Journal of Operations \& Production Management, 23(7), 794-818.

Mikhailov, L., \& Tsvetinov, P. (2004). Evaluation of services using a fuzzy analytic hierarchy process. Applied Soft Computing, 5(1), 23-33.

Min, H., \& Melachrinoudis, E. (1999). The relocation of a hybrid manufacturing/distribution facility from supply chain perspectives: a case study. Omega, 27(1), 75-85.

Özdağoğlu, A., \& Özdağoğlu, G. (2007). Comparison of AHP and fuzzy AHP for the multi-criteria decision making processes with linguistic evaluations. Istanbul Commerce University Journal of Science, 6(11), 65-85.

Saaty, T. L. (1980). The Analytic Hierarchy Process. New York: McGraw-Hill.

Stevenson, W. J. (1993). Production \& Operations Management. Irwin McGraw-Hill.

Tuzkaya, G., Önüt, S., Tuzkaya, U. R., \& Gülsün, B. (2008). An analytic network process approach for locating undesirable facilities: An example from Istanbul, Turkey. Journal of Environmental Management, 88(4), 970-983.

Van Laarhoven P.J. M., \& Pedrcyz, W. (1983). A fuzzy extension of Saaty’s priority theory. Fuzzy Sets and Systems, 11, 229-241.

Wang, J. W., Cheng, C. H., \& Huang, K. C. (2009). Fuzzy hierarchical TOPSIS for supplier selection. Applied Soft Computing, 9(1), 377-386.

Wang, T. C., \& Chang, T. H. (2007). Application of TOPSIS in evaluating initial training aircraft under a fuzzy environment. Expert Systems with Applications, 33, 870-880.

Wang, T. C., \& Chen, Y. H. (2007). Applying consistent fuzzy preference relations to partnership selection. Omega, 35(4), 384-388.

Wang, Y. J., \& Lee, H. S. (2007). Generalizing TOPSIS for fuzzy multiple-criteria group decisionmaking. Computers and Mathematics with Applications, 53, 1762-1772.

Wang, Y. M., \& Elhag, T. M. S. (2006). Fuzzy TOPSIS method based on alpha level sets with an application to bridge risk assessment. Expert Systems with Applications, 31, 309-319.

Wang, Y. M., Yang, J. B., \& Xu, D. L. (2005). A two-stage logarithmic goal programming method for generating weights from interval comparison matrices.Fuzzy sets and systems, 152(3), 475-498.

$\mathrm{Xu}, \mathrm{R}$. (2000). Fuzzy least-squares priority method in the analytic hierarchy process. Fuzzy Sets and Systems, 112(3), 395-404.

Yoon, K. P., \& Hwang, C. L. (1995). Multiple attribute decision making. Thousand Oaks, CA: Sage Publication.

Zadeh LA (1965). Fuzzy sets. Information Control, 8(3), 338-353. 